\title{
PENDAMPINGAN HUKUM UMKM BERBASIS E-COMMERCE DI DESA JARAK, KEC.WONOSALAM, JOMBANG
}

Satria Unggul Wicaksana Prakasa

Agus Supriyo

Fakultas Hukum Universitas Muhammadiyah Surabaya

satria@fh.um-surabaya.ac.id

\section{Submited : Januari 2020 Acepted : Maret 2020 Published : April 2020}

\begin{abstract}
Abstrak
Tumbuhnya industri Usaha Menengah, Kecil, Mikro/UMKM serta kesadaran masyarakat untuk menggerakkan perdagangan berbasis digital (e-commerce) menjadi kunci perekonomian Indonesia stabil. Metode pendampingan hukum UMKM berbasis e-commerce dilakukan dengan kegiatan pelatihan, sosialisasi, dan workshop dengan melibatkan beberapa pihak terkait, seperti perangkat desa, dan asosiasi petani dan peternak sekitar yang mulai dilakukan antara 26 Juli - 26 Agustus 2019, bertempat di Desa Jarak, Kecamatan Wonosalam, Kab. Jombang. Fokus kegiatan pendampingan hukum UMKM berbasis e-commerce adalah bagaimana meningkatkan upaya kesadaran warga Desa Jarak, Kec. Wonosalam, Kab.Jombang untuk memperhatikan aspek legalitas perizinan usaha yang dijalankan, seraya melakukan berbagai macam pengolahan berbagai macam produk olahan yang berasal dari sektor perkebunan dan peternakan, yang dalam hal ini fokus pada produk olahan susu.Komoditas susu sebelumnya tidak memiliki nilai ekonomi, namun dengan diversifikasi olahan susu mampu menjadi nilai tambah bagi UMKM. Selain itu, pemanfaatan potensi alam juga menjadi nilai tersendiri bagi masyarakat Desa Jarak, Kec.Wonosalam, Kab. Jombang untuk menawarkan jasa edu-wisata alam milky village, yang semuanya bergantung pada pemanfaatan maksimal e-commerce dengan pendekatan partisipatoris masyarakat. Kesimpulan dari pendampingan hukum UMKM Berbasis E-commerce adalah Perlu kesadaran kolektif bagi Masyarakat Desa Jarak, Kec.Wonosalam, Kab.Jombang melalui usaha partisipatif antara kelompok usaha masyarakat, ibu rumah tangga, serta karang taruna, dan entitas sosial lainnya untuk menjadikan proses perizinan hukum beserta dokumen-dokumen kelengkapannya dapat dipenuhi, sehingga kepastian hukum dan jaminan bagi konsumen maupun wisatawan dapat terjaga dengan baik. Selain itu, perlu dorongan Pemerintah dan instansi vertikal desa wisata dan geliat UMKM yang semakin tumbuh melalui pemanfaatan e-commerce dengan menggandeng kelompok masyarakat dan perguruan tinggi. Agar, diversifikasi olahan tersebut dapat menambah fnilai komoditas barang dan jasa (wisata) yang ditawarkan, dan mempercepat pertumbuhan ekonomi warga berbasis partisipatoris.
\end{abstract}

Kata Kunci: Pendampingan Hukum, UMKM, e-commerce 


\section{PENDAHULUAN}

Sebagai negara dengan tingkat pertumbuhan Ekonomi berkisar 5,2\% pada tahun 2019 sesuai data dari Bank Dunia (World Bank) yang berjudul "East Asia and Pacific Economic Update October 2019: Weathering Growing Risk". Stabilitas pertumbuhan ekonomi tersebut sangat dipengaruhi oleh stabilitas konsumsi masyarakat dan didukung pertumbuhan pendapatan di beberapa sektor seperti agrikultur, industri, dan jasa. Hal yang lebih penting juga tumbuhnya industri Usaha Menengah, Kecil, Mikro/UMKM (Small Midle Enterprises/SMEs) serta kesadaran masyarakat untuk menggerakkan perdagangan berbasis digital (e-commerce) (World Bank, 2019).

Potensi pertumbuhan e-commerce terbesar di dunia, berdasarkan data Global Web Index dalam Digital 2019 Spotlight: Ecommerce in Indonesia menyebutkan bahwa tingkat aktifitas masyarakat Indonesia terkait penggunaan e-commerce mencapai angka lebih dari $90 \%$ masyarakat Indonesia pengguna internet juga pelaku aktif e-commerce, baik sebagai konsumen maupun produsen. Pengguna e-commerce juga masuk kategori masyarakat usia produktif antara 16-64 tahun membeli barang dan jasa online marketplace system (Simon Kemp \& Sarah Moey, 2019). Hal ini menunjukkan bahwa, potensi penggunaan e-commerce demikian besar di Indonesia.

Pertumbuhan UMKM di Indonesia juga sangat terbantu sebagai dampak positif dalam pemanfaatan platform online guna pemasaran produknya, dimana sebanyak 3,79 juta dari 59,2 juta UMKM atau sekitar kurang lebih 8\% telah memanfaatkan platform e-commerce, dan hal tersebut menjadi penanda perkembangan ekonomi digital di Indonesia yang semakin pesat. Beberapa e-commerce di Indonesia seperti Lazada, Shopee, MatahariMall.com, Blibi. com, Bukalapak.com, Tokopedia.com, Blanja. com, dsb. Dalam hal ini, Pemerintah memberi perlakuan khusus, akses pinjaman lunak, hingga pendampingan untuk tumbuh kembang produk-produk UMKM agar berkualitas, sesuai standarisasi produk, hingga aspek pemasaran (Kementerian Komunikasi dan Informasi RI, 2017).

Selain itu, pengelolaan dan penjualan secara konvensional membuat peternak enggan memanfaatkan e-commerce menjadi faktor ekonomi utama tingkat pendapatan yang sangat minim untuk pengelolaan produk tersebut. Hal tersebut disebabkan, kurang-pahamnya prosedur hukum yang dilakukan dalam hal perizinan, baik dalam hal Perizinan Industri Rumah Tangga (PIRT), maupun hal-hal berkaitan dengan keamanan produk dan perlindungan konsumen, serta pengembangannya dalam pemanfaatan online marketplace system yang ada, termasuk kaitannya dengan data privasi. Pendidikan hukum sangat penting diberikan kepada masyarakat secara komprehensif, sehingga pelaku UMKM memiliki kesadaran dan pemahaman hukum yang komprehensif dalam pemanfaatan e-commerce bagi kesejahteraan masyarakat.

Sejalan dengan isu hukum yang diangkat, pendidikan hukum sangat tepat diberikan kepada masyarakat melalui mekanisme pendampingan bermanfaat bagi pembangunan budaya dan sistem hukum yang sangat penting bagi masyarakat. Hal tersebut memberikan bantuan bagi masyarakat dari kampus untuk perkembangan ekonomi dengan pendekatan dan transformasi kurikulum yang bermanfaat bagi masyarakat, sehingga realitas perguruan tinggi dan perkembangan masyarakat saling berkelindan (Priest, 1983). 


\section{TINJAUAN PUSTAKA}

E-commerce merupakan suatu platform yang digunakan oleh individu atau organisasi untuk melakukan transaksi, menjual, membeli, mentransfer, tukar-menukar barang dan jasa serta sistem informasi yang sangat efektif untuk pembangunan masyarakat dan menjadi solusi atas akses ekonomi masyarakat, sehingga tingkat pertumbuhan ekonomi suatu negara dan ditunjang dengan kesadaran penggunaan gadget sebagai salah satu budaya literasi digital masyarakat (Alyoubi, 2015).

Perkembangan e-commerce sangat dipengaruhi oleh majunya teknologi dan globalisasi yang kemudian berdampak pada tersedianya berbagai macam barang dan jasa yang dijual secara daring dalam berbagai platform yang disediakan oleh e-commerce. Sehingga mempercepat pemenuhan hakhak konsumen, memotong berbagai macam hambatan dalam akses produk, serta menjamin hak-hak fundamental konsumen seperti keamanan konsumen, keamanan data privasi, jaminan kualitas barang/jasa, serta aspek hak kekayaan intelektual (HKI) dari produk yang dijual. Sehingga tercipta hubungangn yang saling menguntungkan antara konsumen dan penjual dalam satu platform yang disepakati pada e-commerce tersebut (Yuthayotin, 2015).

E-commerce melibatkan aktor ekonomi dari berbagai macam jenis dan segmen, yang dapat melakukan transaksi barang dan jasa dari berbagai macam penyedia barang dan jasa, dan dapat disebut "one-stop shops" karena berbagai pilihan barang dan jasa dengan pilihan beragam dan harga murah, serta menciptakan segmen baru (seperti membeli software, music, film, jasa informasi, dsb) yang tidak dapat dibayangkan sebelumnya dalam proses perdagangan konvensional (Dickie, 2015).
Pendampingan hukum merupakan suatu mekanisme yang membantu masyarakat yang tidak paham proses hukum dan perizinan, termasuk dalam aspek usaha dan pendirian UMKM agar tidak terjadi diskriminasi, maladministrasi, hingga mendampingi dokumen yang dibutuhkan sesuai dengan regulasi hukum yang ada (Lee \& Backes, 2018). Proses ini sangat penting bagi masyarakat agar memiliki pemahaman hukum agar tidak terjadi proses yang merugikan UMKM dalam menjual dan memasarkan produk/jasa yang dijual dalam online marketplace system yang disediakan oleh e-commerce.

\section{METODE PENELITIAN}

Metode pendampingan hukum UMKM berbasis e-commerce dilakukan dengan kegiatan pelatihan, sosialisasi, dan workshop dengan melibatkan beberapa pihak terkait, seperti perangkat desa, dan asosiasi petani dan peternak sekitar yang mulai dilakukan antara 26 Juli - 26 Agustus 2019, bertempat di Desa Jarak, Kecamatan Wonosalam, Kab. Jombang. Secara singkat, akan digambarkan profil mitra sebagai berikut:

\section{Profil Mitra}

Desa Jarak, merupakan desa produktif dari 9 desa di Kecamatan Wonosalam, Kabupaten Jombang, Jawa Timur. Kondisi fisik dasar yang dikaji dalam gambaran umum wilayah studi meliputi beberapa aspek, yaitu:

a. Kondisi geografis batas-batas desa jarak

Sebelah utara: Desa Sambirejo, Kecamatan Wonosalam

Sebelah selatan: Desa Galengdowo, Kecamatan wonosalam

Sebelah barat: Desa Wonomerto, 
kecamatan Wonosalam

- Sebelah Timur: Kawasan Perhutani dan

Taman Hutan Raya Raden Suryo

b. Penduduk

Laki-Laki: 1.614, Perempuan: 1.528 Jumlah: 3141

c. Pekerjaan

Petani/ Pekebun : 1.068, Pelajar : 479, Peternak : 285, MRT : 215, Karyawan Swasta : 337, Pegawai Negeri : 11, TNI : 2, Polisi : 1, Wiraswasta : 232

d. Tingkat Pendidikan

SD : 1.218, SLTP : 568, SLTA : 238,

Sarjana : 59

e. Pemeluk Agama

Islam : 2.885, Kristen : 78, Hindu : 179

f. Tempat Ibadah

Masjid: 6, Mushola: 13, Gereja: 2, Pura: 2

g. Kondisi Topogafi: mayoritas berupa hutan dan terletak pada ketinggian $\pm 482 \mathrm{~m}$ diatas permukaan laut.

h. Kondisi Geologi: sebagian besar jenis tanah Desa Jarak berupa tanah alluvial hitam

i. Kondisi Hidrologi: berpotensi dalam penyediaan sumber daya air karena termasuk dalam hulu sungai. Selain itu, terdapat beberapa mata air dengan debit yang sedang.

j. Kondisi Iklim: iklim tropis dengan suhu berkisar antara 25 - 28 celcius

k. Kesuburan Tanah: tingkat kesuburan tanah cukup tinggi karena terletak di dataran tinggi, tepatnya dibagian selatan dan barat Pegunungan Anjasmoro.

1. Pola Penggunaan Lahan: sebagian besar dimanfaatkan untuk perkebunankarena kondisi tanah yang subur, namun terdapat juga pertanian dan peternakan. Hasil pertanian di Desa Jarak meliputi: kopi, cengkeh, kakao, buah-buahan (durian, manggis, alpukat, dll), kayu-kayuan, emponempon (lengkuas, kunyit, Serai, jahe, Lada). $\mathrm{m}$. Potensi Peternakan yang dikembangkan, meliputi: sapi perah, sapi potong, kambing, ayam, burung unggas, entok, dll.

n. Iklim Tolenransi: pada Desa Jarak sangat unik karena agama yang berkembang di masyarakat Desa Jarak terdiri dari Islam, Hindu, dan Kristen.

Potensi Desa Jarak baik secara geografis maupun demografis menjadikan potensi tumbuhnya UMKM dengan pemanfaatan produk perkebunan maupun peternakan. Selain itu, pendampingan hukum juga menjadi faktor penting untuk memberi keamanan dan kepastian dalam beraktifitas pada online marketplace system yang ada, sehingga menjadi nilai tambah bagi masyarakat.

\section{HASIL DAN PEMBAHASAN}

Fokus kegiatan pendampingan hukum UMKM berbasis e-commerce adalah bagaimana meningkatkan upaya kesadaran warga Desa Jarak, Kec.Wonosalam, Kab.Jombang untuk memperhatikan aspek legalitas perizinan usaha yang dijalankan, seraya melakukan berbagai macam pengolahan berbagai macam produk olahan yang berasal dari sektor perkebunan dan peternakan, yang dalam hal ini fokus pada produk olahan susu.

Komoditas susu sebelumnya tidak memiliki nilai ekonomi, namun dengan diversifikasi olahan susu mampu menjadi nilai tambah bagi UMKM. Selain itu, pemanfaatan potensi alam 
juga menjadi nilai tersendiri bagi masyarakat Desa Jarak, Kec.Wonosalam, Kab.Jombang untuk menawarkan jasa edu-wisata alam milky village, yang semuanya bergantung pada pemanfaatan maksimal e-commerce dengan pendekatan partisipatoris masyarakat.

\section{Pendampingan Hukum UMKM}

Sosialisasi pendampingan hukum UMKM difokuskan kepada topik-topik praktis yang ditujukan agar masyarakat yang telah memiliki kelompok usaha dapat meningkatkan jenis usahanya dengan aman dan memiliki kepastian hukum, seperti: perizinan legalitas UMKM berupa: Tanda Daftar Perusahaan (TDP), Surat Izin Usaha Perdagangan (SIUP), Nomor Pokok Wajib Pajak (NPWP), Izin Gangguan, serta Izin Produk Industri Rumah Tangga (P-IRT), dan hal tersebut menjadi perhatian untuk penjualan komoditas barang maupun jasa dalam e-commerce yang secara hukum juga berpotensi dipersyaratkan, sehingga warga Desa Jarak, Kec.Wonosalam, Kab.Jombang memiliki kesadaran hukum untuk mengurus perizinan tersebut.
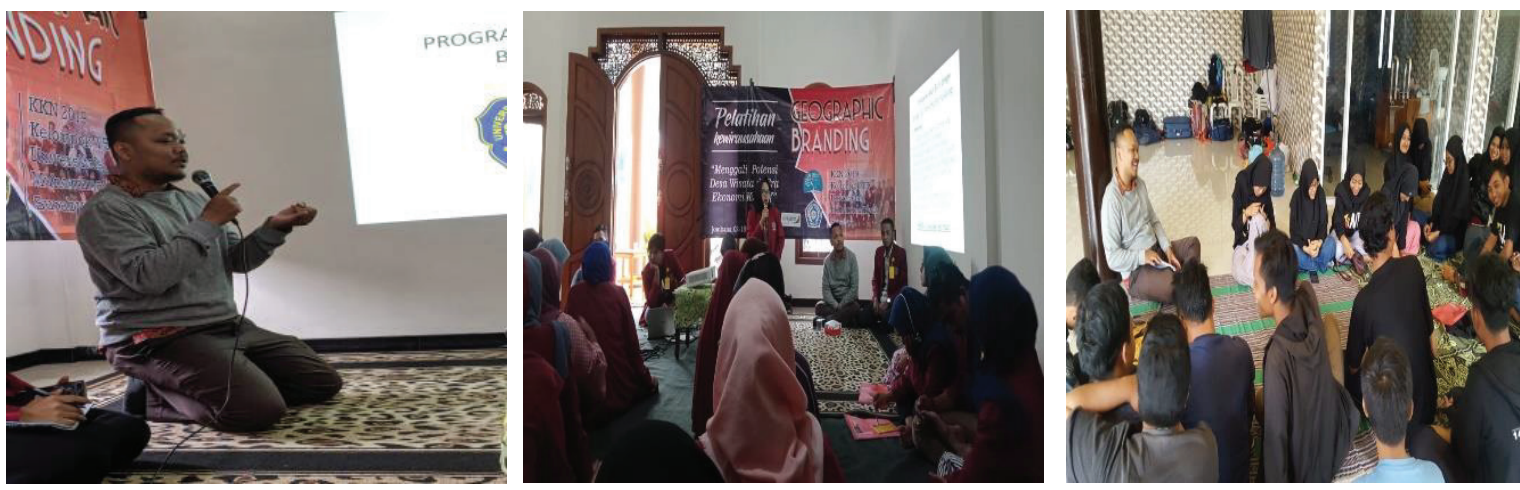

Gambar 1: Sosialisasi Pendampingan hukum bagi UMKM bersama warga Desa Jarak, Kec.Wonosalam, Kab.Jombang

Warga Desa Jarak, Kec.Wonosalam, Kab. Jombang yang tergabung dalam kelompok usaha peternak susu cukup sadar atas perizinan usaha untuk pendirian UMKM tersebut, namun dengan alasan tidak adanya waktu untuk mengurus perizinan, mengingat lokasi Kecamatan Wonosalam berada di dataran tinggi Gunung Anjasmoro, akses informasi yang kurang maksimal yang didapatkan oleh Pemerintah Desa, sehingga edukasi kepada masyarakat yang terpadu tentang kesadaran untuk pengurusan perizinan, menjadikan proses tersebut belum maksimal dijalankan.

\section{Pemanfaatan E-commerce Bagi Pengem- bangan Produk Susu \& Edu-Wisata Milky Village}

Wilayah kecamatan Wonosalam berada di kawasan pegunungan Anjasmoro yang memiliki sumberdaya yang melimpah. Kekayaan sumberdaya yang melimpah ini belum dimanfaatkan secara optimal oleh penduduk sekitar, karena memang sumberdaya manusia masih sangat terbatas. Dalam hal ini, mata pencaharian penduduk mayoritas bertani dan berkebun. Kawasan Wonosalam adalah daerah pegunungan dan masyarakatnya banyak menggeluti UMKM (Rohim \& Kurniawan, 2017). Sehingga, baik produk olahan hasil kekayaan alam maupun sektor wisata menjadi menarik dan memiliki potensi ekonomi yang terus dapat dikembangkan. 
Potensi olahan susu, jika serius dilakukan pengembangan dan diversifikasi model komoditas makanan atau minuman olahan susu, serta pengembangan edu-wisata milky village coba disosialisasikan bersama warga dengan menggandeng pihak-pihak terkait seperti kelompok usaha peternak sapi dan karang taruna, setidaknya ada beberapa gagasan untuk pengembangan dengan pemanfaatan e-commerce, yaitu:

\section{Edu-Wisata Milky Village: usaha partisipatif} masyarakat dan mahasiswa UMSurabaya dengan pemanfaatan potensi alam desa, membranding desa wisata, memasang plang yang mengarah menuju ke desa, juga perlahan mulai memetakan lokasi wisata dari tempat memerah, mengepul susu dan lain sebagainya, yang tidak kalah penting melalui kanal YouTobe dan Instagram mencoba memasarkan jasa edu-wisata secara daring. Sehingga, akses informasi wisatawan semakin terbuka.

2. Produk-produk diversifikasi olahan susu yang dibuat kolaboratif bersama warga dan mahasiswa, melalui:

a. kerupuk susu (milky Chips) - kerupuk ini terbuat dari bahan rempah alami dan susu asli, kerupuk susu ini akan dijual dengan dua cara yaitu yang sudah digoreng dan belum digoreng, yang sudah digoreng dijual seharga Rp.15.000,- dengan berat besrsih $150 \mathrm{~g}$ dan yang belum digoreng dijual seharga Rp.10.000,- dengan berat bersih $120 \mathrm{~g}$.

b. Cireng susu (ACISU) - cireng susu adalah salah satu inovasi dimana cireng ini memiliki bahan dasar yang sama dengan kerupuk susu, hanya saja cara pengolahannya yang sedikit berbeda. Cireng susu ini juga dikemas sebagai makanan frozen food dengan mika tebal yang berisi 15 biji, dan dijual seharga Rp. 7.000,-.

c. Puding susu kenyot (Punyott) - puding susu kenyot adalah turunan dari puding susu, namun bisa dinikmati dengan cara dikenyot. Puding susu sedit ini memiliki tekstur yang lembut dan menarik dengan rasa yang nikmat. Puding susu sedot olahan kami dijual seharga Rp.7.000,dengan berat $250 \mathrm{ml}$.

d. Fruta Milky - fruta milky adalah olahan susu dari susu dan buah asli, sebelumnya mungkin sudah ada olahan susu dengan perasa bubuk, dan kini kelompok kkn kami mencoba untuk menggunakan rasa dari buah langsung, setiap jelasnya kami menjual dengan harga Rp.10.000,-

Selama ini, memang ada akses yang disediakan Pemerintah Kabupaten Jombang dalam pemaksimalan potensi Wisata dan UMKM pada wilayah Kec.Jombang, khususnya pada Desa Jarak pada website pemerintah. Namun daya jangkau (visibility) sangat terbatas, apalagi potensi yang ada baik potensi alam maupun produk dari hasil peternakan yang melimpah ruah belum secara maksimal dimanfaatkan

Pemkab Jombang wajib memiliki inisiasi untuk mendorong pelaku UMKM dan kelompok masyarakat memanfaatkan platform online marketplace systems yang umumnya digunakan oleh khalayak luas, sehingga daya 

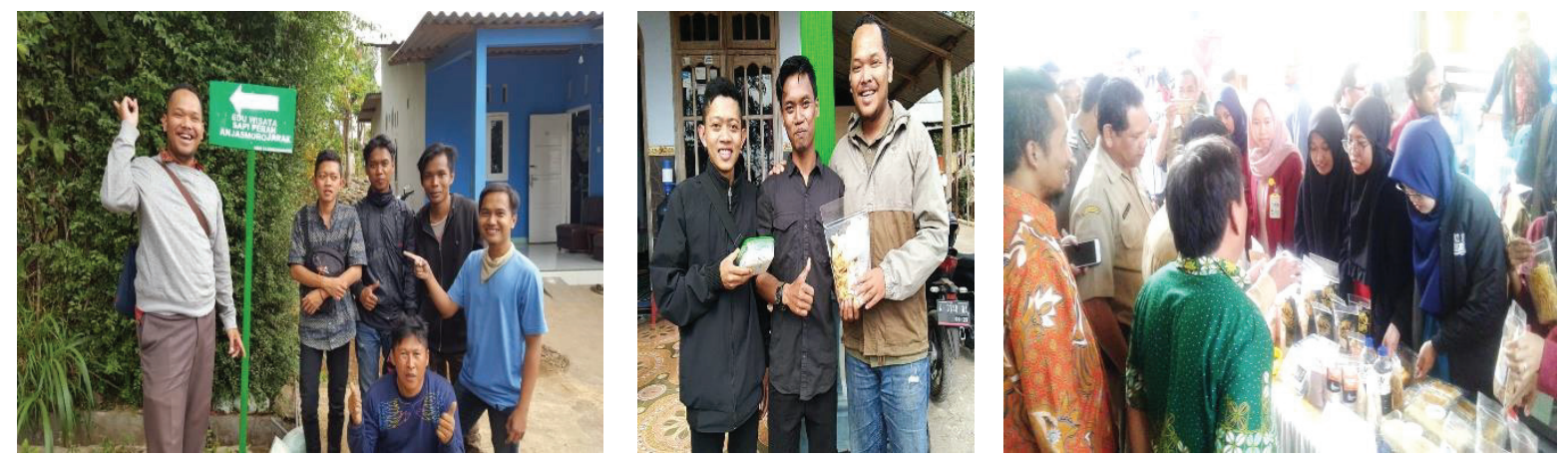

Gambar 2: Pemanfaatan Produk Olahan Susu serta Pengembangan Edu-Wisata Milky Village bersama warga Desa Jarak, Kec. Wonosalam, Kab.Jombang
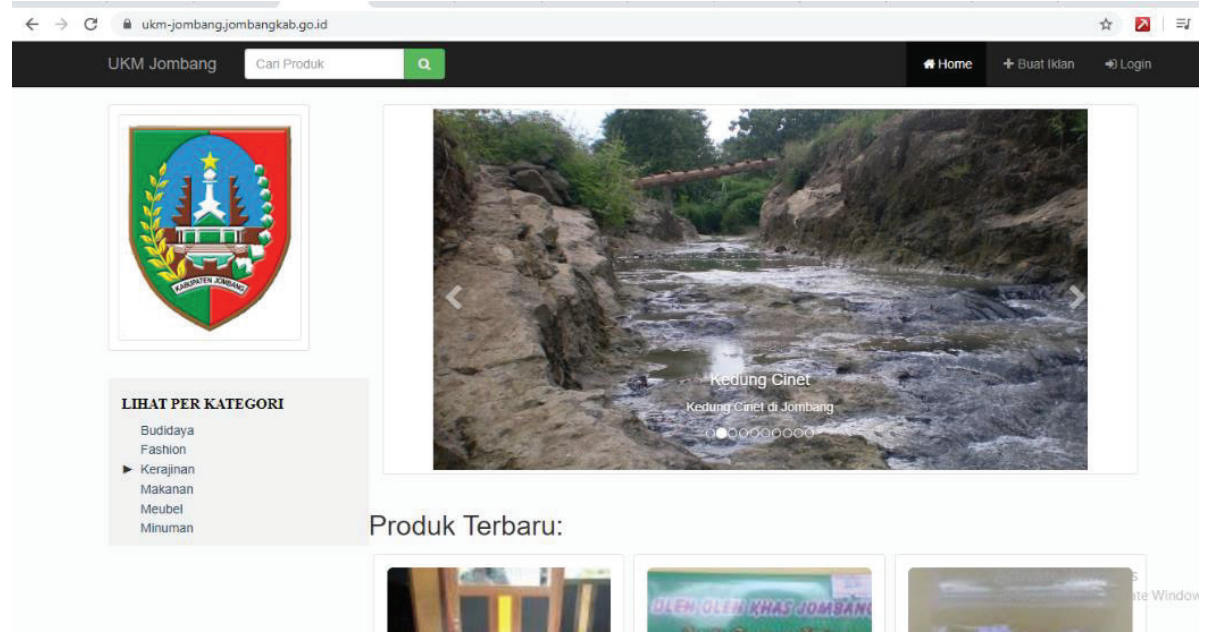

Gambar 3: Website Pemerintah Kabupaten Jombang dalam Promosi Wisata maupun Produk UMKM dari Warga Jombang, pada https://ukm-jombang.jombangkab.go.id/

beli produk olahan susu dan daya pemanfaatan akses edu-wisata milky village dapat terlaksana dengan maksimal dan mendorong pertumbuhan ekonomi masyarakat semakin baik.

\section{KESIMPULAN}

Perlu kesadaran kolektif bagi Masyarakat Desa Jarak, Kec.Wonosalam, Kab.Jombang melalui usaha partisipatif antara kelompok usaha masyarakat, ibu rumah tangga, serta karang taruna, dan entitas sosial lainnya untuk menjadikan proses perizinan hukum beserta dokumen-dokumen kelengkapannya dapat dipenuhi, sehingga kepastian hukum dan jaminan bagi konsumen maupun wisatawan dapat terjaga dengan baik,

Selain itu, perlu dorongan Pemerintah dan instansi vertikal untuk pengembangan Desa Jarak, Kec.Wonosalam, Kab.Jombang sebagai desa wisata dan geliat UMKM yang semakin tumbuh melalui pemanfaatan e-commerce dengan menggandeng kelompok masyarakat dan perguruan tinggi. Agar, diversifikasi olahan tersebut dapat menambah fnilai komoditas barang dan jasa (wisata) yang ditawarkan, dan mempercepat pertumbuhan ekonomi warga berbasis partisipatoris. 


\section{UCAPAN TERIMAKASIH}

Ucapan terima kasih kepada Pemerintah dan Warga Desa Jarak, Kec.Wonosalam, Kab.Jombang. Serta mahasiswa bimbingan Kuliah Kerja Nyata (KKN) Universitas Muhammadiyah Surabaya tahun 2019 Kelompok 14 yang telah melakukan pendampingan dan pengumpulan data yang dibutuhkan dalam penelitian ini.

\section{DAFTAR PUSTAKA}

Adriyani, F. N. (2016). Higiene Sanitasi, Kualitas Fisik Dan Bakteriologi Susu Sapi Segar Perusahaan Susu X Di Surabaya. Jurnal Kesehatan Lingkungan (JKL) Universitas Airlangga, 36-47.

Alyoubi, A. A. (2015). E-commerce in Developing Countries and How to Develop Them During the Introduction of Modern Systems. Procedia Computer Science, 65, 479 - 483.

Dickie, J. (2015). Producers and Consumers in EU E-Commerce Law. Oregon: Hart Publishing.

Kementerian Komunikasi dan Informasi RI. (2017, 11 17). Kominfo.go.id. Retrieved from Kemenkop UKM: 3,79 Juta UMKM Sudah Go Online: https://www.kominfo.go.id/content/ detail/11526/kemenkop-ukm-379juta-umkm-sudah-go-online/0/ sorotan_media

Lee, J. G., \& Backes, B. L. (2018). Civil legal aid and domestic violence: A review of the literature and promising directions. Journal of Family Violence, 33(6), 421-433.
Priest, G. L. (1983). Social science theory and legal education: The law school as university. Journal of Legal Education, 33(3), 437-441.

Rohim, A., \& Kurniawan, I. (2017). Manajemen Usaha Dan Produksi Pada Usaha Mikro, Kecil Dan Menengah (UMKM) Di Desa Carang Wulung Wonosalam . Comvice : Journal of community service, 25-28.

Simon Kemp \& Sarah Moey. (2019, September 18). Global Web Index. Retrieved from Data Reportal; Digital 2019 Spotlight: Ecommerce in Indonesia: https:// datareportal.com/reports/digital-2019ecommerce-in-indonesia

World Bank. (2019). World Bank East Asia and Pacific Economic Update, October 2019 : Weathering Growing Risks. Washington. DC: World Bank. Retrieved from https://openknowledge. worldbank.org/handle/10986/32482

Yuthayotin, S. (2015). Access to Justice in Transnational B2C E-Commerce. London: Springer International Publishing. 